\title{
DUPLICAÇÃO URETRAL EM HOMEM ADULTO
}

\section{URETHRAL DUPLICATION IN ONE ADULT MALE}

\author{
Marcelo Leite Ottoni' ${ }^{1}$; Maria Cristina Dornas ${ }^{2}$; Irineu Rubstein, TCBC-RJ ${ }^{3}$; \\ Carlos Alberto Basílio de Oliveira, TCBC-RJ ${ }^{4}$; Antonio Carlos Iglesias, TCBC-RJ ${ }^{5}$
}

\section{INTRODUÇÃO}

A duplicação uretral (DU) é uma anomalia congênita de ocorrência rara, cuja descrição inicial coube a Aristóteles. A apresentação clínica tem características próprias conforme o tipo de variação anatômica presente. É mais comum em homens e o diagnóstico é feito geralmente durante a infância ${ }^{1,2}$. A DU pode ser completa ou parcial, sendo observada freqüentemente no plano sagital com uma uretra dorsal e outra ventral ${ }^{2,3}$. Algumas formas de duplicação uretral acompanham-se de outras mal-formações como, por exemplo, a extrofia vesical, a hipospádia ou epispádia e a criptorquidia ${ }^{2,4}$. O objetivo deste trabalho é apresentar e discutir os achados clínicos, o diagnóstico e o tratamento de um caso de duplicação uretral completa em homem adulto.

\section{RELATO DO CASO}

Paciente de 28 anos de idade, do sexo masculino, branco, procurou atendimento médico no Hospital Universitário Gaffrée e Guinle e relatou que durante a micção, concomitantemente à saída de urina pelo meato uretral, ocorria saída de líquido com as mesmas características através de um orifício situado na região dorsal do pênis. Refere que desde há muitos anos já havia percebido tal fato.

À inspeção, identificou-se meato uretral localizado no ápice da glande e um segundo orifício de pequena dimensão situado no dorso do pênis na junção dos $2 / 3$ proximais com o 1/3 distal (Figura 1). À observação da micção pode-se constatar saída simultânea de urina pelos meatos, tópico e epispádico. Não havia qualquer outra alteração da genitália externa e o toque retal identificou próstata normal. A exploração instrumental do meato epispádico permitiu a fácil introdução por cerca de $15 \mathrm{~cm}$ de cateter ureteral de $n^{\circ} 8$ Fr.

A uretrocistografia evidenciou uretra e bexiga de características normais. A injeção de contraste através o meato epispádico demonstrou estrutura canalicular, originada em situação dorsal na porção membranosa da uretra ventral e apresentando curso independente desta (Figura 2). A ultrasonografia do aparelho urinário alto não evidenciou qualquer outra anormalidade. A uretrocistoscopia feita através da uretra ventral mostrou-a de calibre normal, identificou o veromontanum e revelou a bexiga de aspecto habitual.

O paciente foi operado para excisão da uretra dorsal acessória por meio de acesso peniano e retropúbico (Figura 3). A evolução pós-operatória transcorreu sem anormalidades.

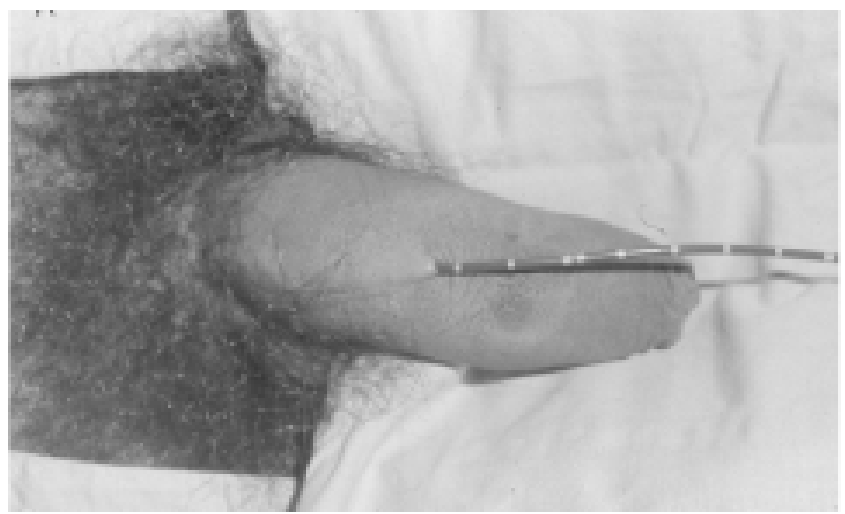

Figura 1 - Verifica-se meato epispádico por onde se introduziu cateter ureteral $8 \mathrm{Fr}$.

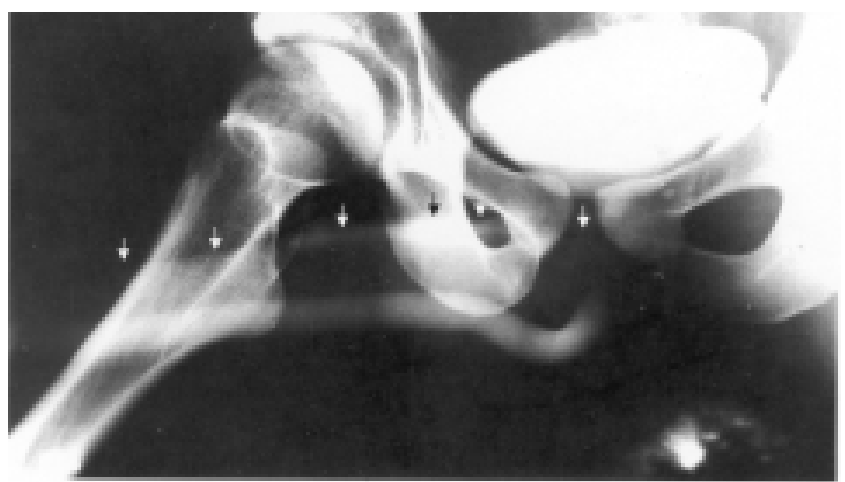

Figura 2 - Uretrocistografia revela duplicidade uretral do tipo IIA2, com a uretra supranumerária (setas) originando-se da uretra normal, apresentando curso e meato independente desta.

1. Ex-Residente de Cirurgia do Hospital Universitário Gaffré-Guinle

2. Residente de Cirurgia do Hospital Universitário Gaffrée-Guinle

3. Professor Adjunto-Doutor; Responsável pela Disciplina de Urologia da Escola de Medicina e Cirurgia - Universidade Federal do Estado do Rio de Janeiro - UNIRIO.

4. Professor Titular da Disciplina de Anatomia Patológica da Escola de Medicina e Cirurgia - Universidade Federal do Estado do Rio de Janeiro - UNIRIO.

5. Professor Titular da Disciplina de Clínica Cirúrgica da Escola de Medicina e Cirurgia - Universidade Federal do Estado do Rio de Janeiro - UNIRIO.

Recebido em 01-06-2005

Aceito para publicação em 15-07-2005

Fonte de financiamento: nenhum

Conflito de interesses: nenhuma

Trabalho realizado no Hospital Universitário Gaffrée e Guinle. 
O exame anatomo-patológico revelou formação cilíndrica, de consistência elástica, medindo $18 \mathrm{~cm}$ de comprimento e $0,3 \mathrm{~cm}$ de diâmetro, com a presença de luz em toda sua extensão. $\mathrm{O}$ exame microscópico identificou características histológicas do sistema urinário de excreção condizente com uretra supranumerária (Figura 4).

\section{DISCUSSÃO}

A DU é uma anomalia congênita rara, tendo cerca de 200 casos descritos na literatura médica; é mais comum no sexo masculino e tem poucos casos descritos em mulheres ${ }^{2-4}$. A variante dorsal é frequientemente a menos funcional e, quando funcional, está associada à incontinência urinária ${ }^{4}$.

Diversas teorias tentam explicar o aparecimento da DU, entretanto, uma única teoria seria incapaz de justificar os diferentes tipos morfológicos com que esta mal-formação se apresenta ${ }^{2-4}$.

De acordo com a classificação proposta por Effmann et al e utilizada por Salle $e t a l^{2}$, a DU pode ser: Tipo I - DU incompleta em fundo cego ou uretra acessória; o Tipo IA, mais comum, caracteriza-se por uretra acessória que se abre em situação ventral ou dorsal no pênis mas não tem comunicação com a uretra ou a bexiga; o Tipo IB é de localização proximal e pode ser difícil diferenciá-lo de um divertículo uretral ou de um ducto de Cowper, na qual a uretra acessória abre-se a partir da uretra e termina em fundo cego no tecido periuretral. O Tipo II representa duplicação uretral completa e patente. O Tipo II-A1 caracteriza os casos de uretra não comunicantes de origem independente na bexiga. $\mathrm{O}$ caso ora descrito inclui-se no Tipo II-A2, ou seja, DU completa no qual o segundo canal tem origem na uretra ventral, percorre de forma independente trajeto dorsal a esta e abre-se num segundo meato, no caso em discussão, um meato epispádico. $\mathrm{Na}$ presente circunstância, o predomínio funcional era da uretra ventral. O Tipo II-B representa as situações em que duas uretras têm origem vesical e fundem-se distalmente terminando em um único meato. Finalmente o Tipo III, no qual a duplicação uretral faz parte da duplicação caudal parcial ou completa.

O significado clínico da DU é variável, de forma que pacientes com DU completa podem ser assintomáticos ou apresentar jato urinário duplo, incontinência urinária, infecção urinária de repetição ou obstrução à micção. Destes, a queixa mais comum é a do jato duplo. Contrariamente ao que é descrito pelos autore ${ }^{1-5}$, o paciente em questão apresentou a particularidade de ter o diagnóstico firmado somente na vida adulta, apesar da existência de jato urinário duplo desde a infância.

Podesta et $a l^{4}$ acreditam que a uretrocistografia é importante para o diagnóstico, no entanto, reservam seu emprego para os casos em que a cistouretrografia miccional não é capaz de demonstrar a uretra acessória hipoplásica. Na ava-

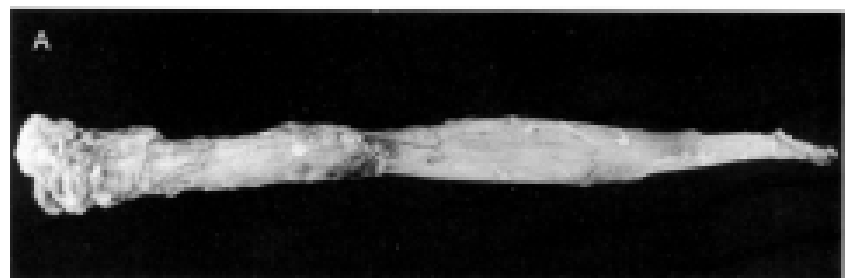

Figura 3 - Peça cirúrgica da uretra supranumerária.

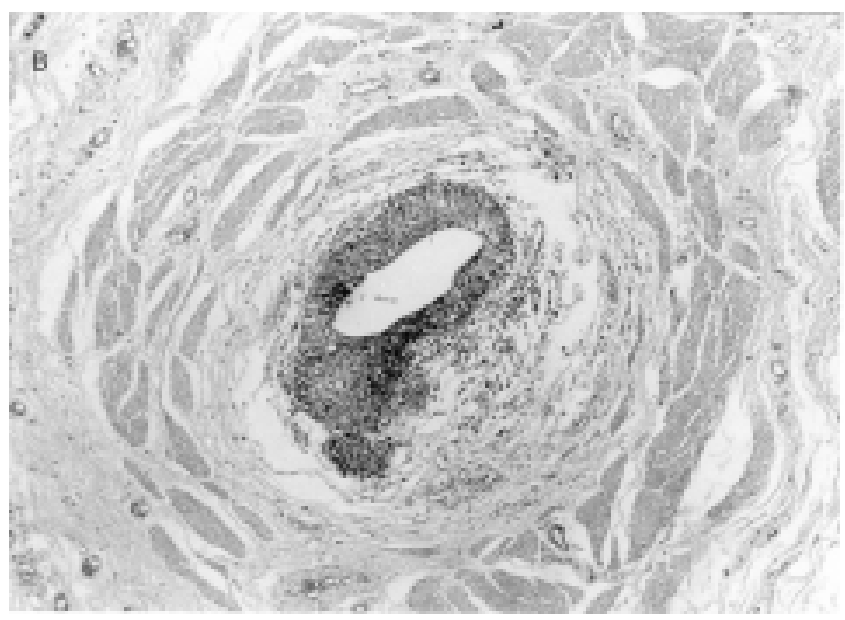

Figura 4 - Fotomicrografia da uretra supranumerária onde se observa a luz revestida por mucosa constituída por epitélio de transição e submucosa com tecido conjuntivo e musculatura lisa.

liação do presente paciente, optou-se pela realização da uretrocistografia, combinada com o estudo contrastado do canal acessório, o que permitiu não só o diagnóstico da DU como possibilitou sua classificação. A uretrocistoscopia pode ser empregada para confirmar o diagnóstico radiológico ${ }^{2}$, como o observado no caso presente. O estudo do aparelho urinário alto deve ser feito preferentemente pela ultra-sonografia com a finalidade de identificar outras mal-formações. A urografia excretora ficaria reservada para os casos de duplicação uretral associada à duplicação vesical, com objetivo de melhor avaliar o trajeto dos ureteres ${ }^{2}$.

Os pacientes assintomáticos, de forma consensual, não necessitam de tratamento, ficando este restrito aos sintomáticos ou para aqueles com problemas estéticos significativos como, por exemplo, o meato de localização epispádica ${ }^{2-4}$. Para a circunstância em discussão, a melhor forma de tratamento é a excisão cirúrgica da uretra dorsal hipoplásica, que deve ser abordada por via peniana, por vezes, combinada com o acesso retropúbico ${ }^{2,4,5}$, como o por nós empregado. No presente caso não houve nenhuma complicação pós-operatória. A evolução do paciente até por volta do $14^{\circ}$ mês após a operação mostrou-o assintomático e sem qualquer tipo de intercorrência.

\footnotetext{
ABSTRACT

Urethral duplication is a rare congenital anomaly. The clinical presentation and treatment varies because of the different anatomical patterns of this abnormality. We report a case of this entity in the adult male patient. The clinical, radiological and endoscopic findings, as well as the treatment are discussed (Rev. Col. Bras. Cir. 2006; 33(5): 336-338).
}

Key words: Epispadias; Urethra/ abnormalities. 


\section{REFERÊNCIAS}

1. Al-Wattar KM. Congenital prepubic sinus: an epispadiac variant of urethral duplication: case report and review of the literature. J Pediatr Surg. 2003; 38(4):E10.

2. Salle JLP, Sibai H, Rosenstein D, Brzezinski AE, Corcos J. Urethral duplication in the male: review of 16 cases. J Urol. 2000; 16396):1936-40.

3. Podesta ML, Medel R, Castera R, Ruarte C. Urethral duplication in children: surgical treatment and results. J Urol. 1998;160(5):1830-3.

4. Erdil H, Mavi A, Erdil s, Gumusburun E. Urethral duplication. Acta Med Okayama. 2003; 57(2):91-3.

5. Arda IS, Hicsonmez A. An unusual presentation of Y-type urethral duplication with perianal abscess: case report. J Pediatr Surg. 2003; 37(8):1213-5.

\section{Como citar este artigo:}

Ottoni ML, Dornas MC, Rubstein I, Oliveira CAB, Iglesias AC. Duplicação uretral em homem adulto. Rev Col Bras Cir. [periódico na Internet] 2006 Set-Out;33(5). Disponível em URL: www.scielo.br/ rcbc

Endereço para correspondência:

Antonio Carlos Iglesias

Rua Jorge Rudge 120, B1. 02, Apto. 1007

Rio de Janeiro - RJ

CEP: 20550-220

E-mail: iglesias@momentus.com.br 